\title{
Theoretical and Experimental Fatigue Strength Calculations of Lips Compensating Circumferential Backlash in Gear Pumps
}

\author{
Piotr Osiński *(D), Grzegorz Chruścielski and Leszek Korusiewicz (D) \\ Faculty of Mechanical Engineering, Wrocław University of Science and Technology, ul. Ignacego Łukasiewicza 5, \\ 50-371 Wrocław, Poland; grzegorz.chruscielski@pwr.edu.pl (G.C.); leszek.korusiewicz@pwr.edu.pl (L.K.) \\ * Correspondence: piotr.osinski@pwr.edu.pl
}

Citation: Osiński, P.; Chruścielski, G.; Korusiewicz, L. Theoretical and Experimental Fatigue Strength Calculations of Lips Compensating Circumferential Backlash in Gear

Pumps. Energies 2021, 14, 251.

https://doi.org/10.3390/en14010251

Received: 27 November 2020 Accepted: 31 December 2020 Published: 5 January 2021

Publisher's Note: MDPI stays neutral with regard to jurisdictional clai$\mathrm{ms}$ in published maps and institutional affiliations.

Copyright: $(\odot 2021$ by the authors. Licensee MDPI, Basel, Switzerland. This article is an open access article distributed under the terms and conditions of the Creative Commons Attribution (CC BY) license (https:// creativecommons.org/licenses/by/ $4.0 /)$.

\begin{abstract}
This article presents theoretical and experimental calculations of the minimum thickness of a compensation lip used in external gear pumps. Pumps of this type are innovative technical solutions in which circumferential backlash (clearance) compensation is used to improve their volumetric and overall efficiency. However, constructing a prototype of such a pump requires long-lasting research, and the compensation lip is its key object, due to the fact that it is an element influenced by a notch and that it operates in unfavorable conditions of strong fatigue stresses. The theoretical calculations presented in this article are based on identifying maximum stress values in a fatigue cycle and on implementing the stress failure condition and the conditions related to the required value of the fatigue safety factor. The experimental research focuses on static bending tests of the lips as well as on the fatigue loading of the lips in series of tests at increasing stress values until lip failure due to fatigue. The tests allowed the minimum lip thickness to be found for the assumed number of fatigue cycles, which is 2.5 times the number of cycles used in wear margin tests.
\end{abstract}

Keywords: circumferential compensation; fatigue strength; gear pump; lips compensating

\section{Introduction}

Modern gear unit designs are being developed with an aim to increase working pressure [1-3], while reducing energy-consumption [4], efficiency pulsation, dynamic loads [5], mass [6] and noise emissions to the environment [7]. Increasing the efficiencies of pumps, whose power may be as high as several tens of kilowatts, entails not only lower operating costs, but also, indirectly, reduced carbon dioxide emissions to the environment. Working pressures in a hydraulic system have a significant influence on the efficiency of the entire installation [2]. The currently designed hydrostatically driven machines and devices demonstrate a trend for increasing the discharge pressures of displacement pumps while reducing the flow rate of the working medium [8]. The flow velocity of the working fluid significantly influences the losses observed in the ducts, as well as in the hydraulic and fastening elements. The energy-consumption of a system is also significantly influenced by the total efficiency of a displacement unit [9-13]. Total pump efficiency describes the relationship between the output (hydraulic) power $N_{h}$ and the input (mechanical) power $N_{m}$ or is defined by the product of the volumetric efficiency $\eta_{v}$ and the hydromechanical efficiency $\eta_{h m}$.

$$
\eta_{c}=\frac{N_{h}}{N_{m}}=\eta_{v} \cdot \eta_{h m}
$$

The mechanical (input) power $N_{m}$ is defined as the product of the torque $M$ and the rotational speed $\omega$ of the drive motor coupled to the gear pump.

$$
N_{m}=M \cdot w
$$


The output (hydraulic) power $N_{h}$ is transmitted to the hydraulic drive system by a pump. It depends on the oil flow through the outlet hole $Q_{r z}$ and the pressure increase $\Delta p$. The pressure rise $\Delta p$ is a subtraction between the outlet pressure and the inlet pressure.

$$
N_{h}=Q_{r z} \cdot \Delta p
$$

The above equation clearly shows that the power transmitted to the hydraulic system $N_{h}$ is influenced by the actual capacity $Q_{r z}$. The actual capacity $Q_{r z}$ directly depends on the volumetric efficiency $\eta_{v}$. The volumetric efficiency $\eta_{v}$ defines the internal hermeticity of the pump and is defined as the relationship between the actual capacity $Q_{r z}$ and the theoretical capacity $Q_{t}$. The parameter $\Delta Q$ defines real volumetric losses occurring in each pump [7]. The level of these losses mostly depends on the types of gaps characteristic of a particular pump design [2].

$$
\eta_{v}=\frac{Q_{r z}}{Q_{t}}=\frac{Q_{t}-\Delta Q}{Q_{t}}
$$

In theory, the hydromechanical efficiency of displacement pumps is defined as the relationship between the theoretical moment $M_{t}$ and the actual moment $M_{r z}$ [7].

$$
\eta_{h m}=\frac{M_{t}}{M_{r z}}=\frac{M_{t}}{M_{t}+\Delta M}
$$

The above relationship indicates that the value of the actual moment $M_{r z}$ which should be applied to the shaft of the driven unit is greater than the value of the theoretical moment $M_{t}$ by a certain value of losses $\Delta M$ which occur in each pump. Therefore, the variable $\Delta M$ describes a certain moment of hydromechanical losses caused by the losses related to friction forces in the working liquid as well as by mechanical losses occurring in the bearings of the engaged gear surfaces and in the gears interacting with the bodies of slide bearings and with the body of the pump.

In modern designs, radial backlash is compensated by using circumferential compensation (Figure 1a) or by providing additional sealing on the suction zone (Figure 1b) as a result of pushing the gears under the influence of hydrostatic pressure [14,15]. In such case, the pushing of the gears towards the suction side within the bearing backlash causes a sickle-shaped gap to be formed on the pressure side (Figure 1b). Meanwhile, as the pump is wearing in, the material on the suction side in the pump body is "milled" by the gears. In typical pumps, the milling depth is approximately $0.1 \mathrm{~mm}$. As a result, the sickle-shaped gap in its widest point and with allowance for the measurement tolerance between the gear circumference and the body sump diameter is approximately $0.15 \mathrm{~mm}$. The formation of this gap limits the distance at which pressure increases along the circumference. In effect, gear pumps with additional sealing provide a discharge pressure of $30 \mathrm{MPa}$ over a short distance. By taking into consideration the criterion of internal hermeticity it is possible to observe that the greatest volumetric efficiency is obtained in the case of units with the smallest gap width but the greatest gap length. In units with circumferential backlash compensation, the value of the backlash along the circumference of the engaged gears and the pump body is constant and does not depend on the shift of the gears towards the suction side. The circumferential compensation is always pressed against the teeth points by the pressure provided through narrow channels diverging from the pressure channel. By improving the sealing with the circumferential backlash compensation (Figure 1c), it is possible to increase the discharge pressure to $40 \mathrm{MPa}$.

The advantages of using circumferential compensation are most clearly observed in the case of low rotational speeds [1]. Figures 2 and 3 show selected characteristics of the volumetric and total efficiencies for the conventional pump and for the prototypes with circumferential compensation. The aspect of how circumferential compensation influences pump efficiency depending on the discharge pressure and the rotational speed is discussed in more detail in $[1,2]$. 
a)
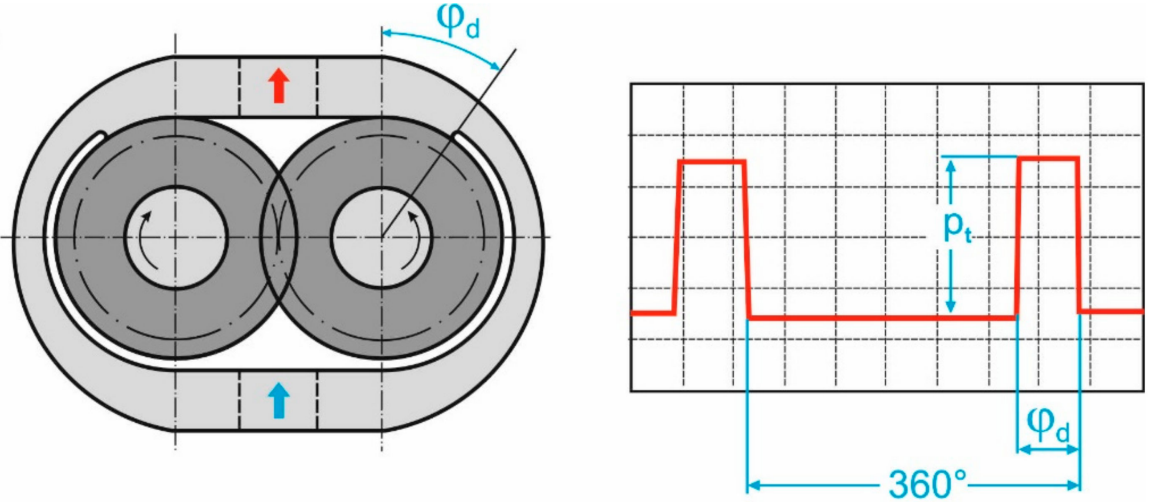

b)
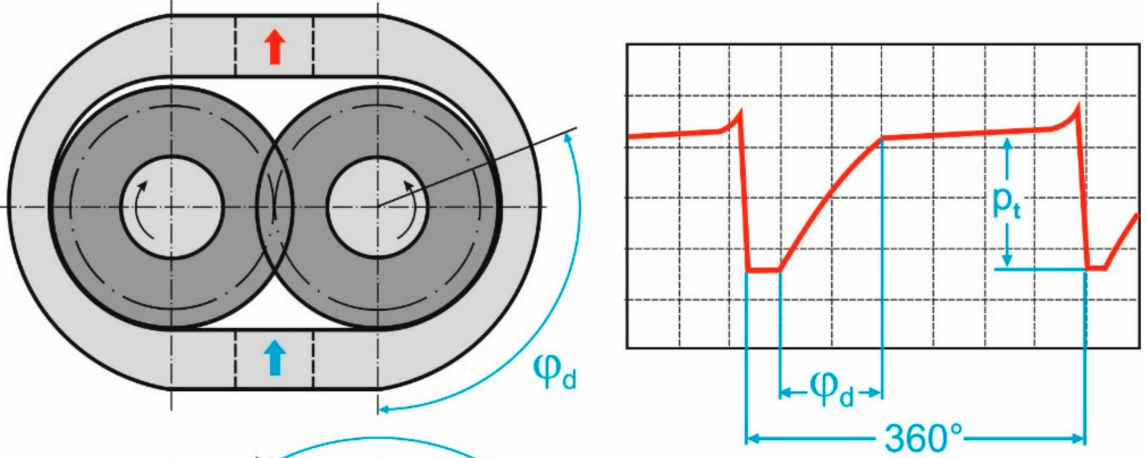

c)
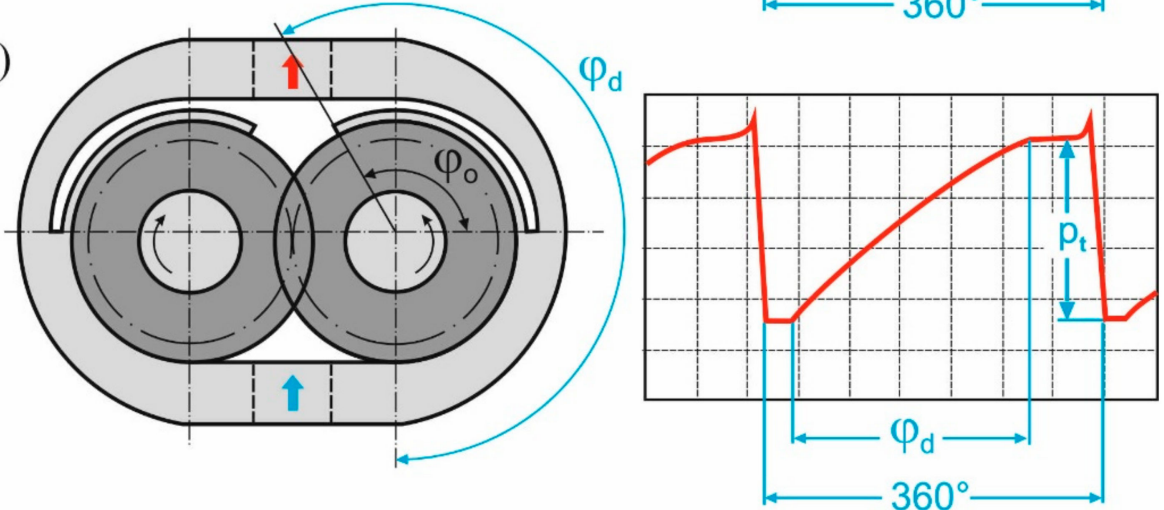

Figure 1. Schematic diagram of circumferential gear sealing together with the changes of the circumferential pressure measured in the tooth space as a function of the rotation angle of the gear: (a) pump with radial backlash compensation, (b) pump with gears shifted from the hydrostatic pressure of the liquid, (c) pump with circumferential backlash compensation. Indications: $\varphi_{\mathrm{o}}-$ wrapping

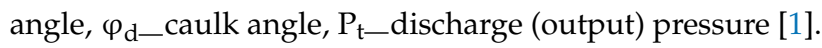

Analyzing the static characteristics of the volumetric efficiency $\eta_{v}$, we can see that the amount of hydraulic energy $N_{h}$ transferred to the hydraulic system by the pump depends on its internal tightness (represented by the caulk angle).

This implies that the gear pumps with circumferential backlash compensation transfer, for the analyzed rotational speed and working pressures above $20 \mathrm{MPa}$, from $35 \%$ to $40 \%$ more energy than in the case of conventional solutions without circumferential backlash compensation (Figure 2). Regarding the input (mechanical) power $N_{m}$, the overall pump efficiency $\eta_{c}$ for pressures above $20 \mathrm{MPa}$ is higher than $30-35 \%$ (Figure 3 ). The value of the increase in total efficiency $\eta_{c}$ is lower than the value of the increase in volumetric efficiency $\eta_{v}$ due to higher hydraulic and mechanical losses resulting from caulk. The above results were obtained for prototype pumps with circumferential backlash compensation. Currently, pump manufacturers do not offer pumps with circumferential backlash compensation. These pumps are at the prototyping stage. The prototype research is focused on ensuring high durability of the compensating elements. 


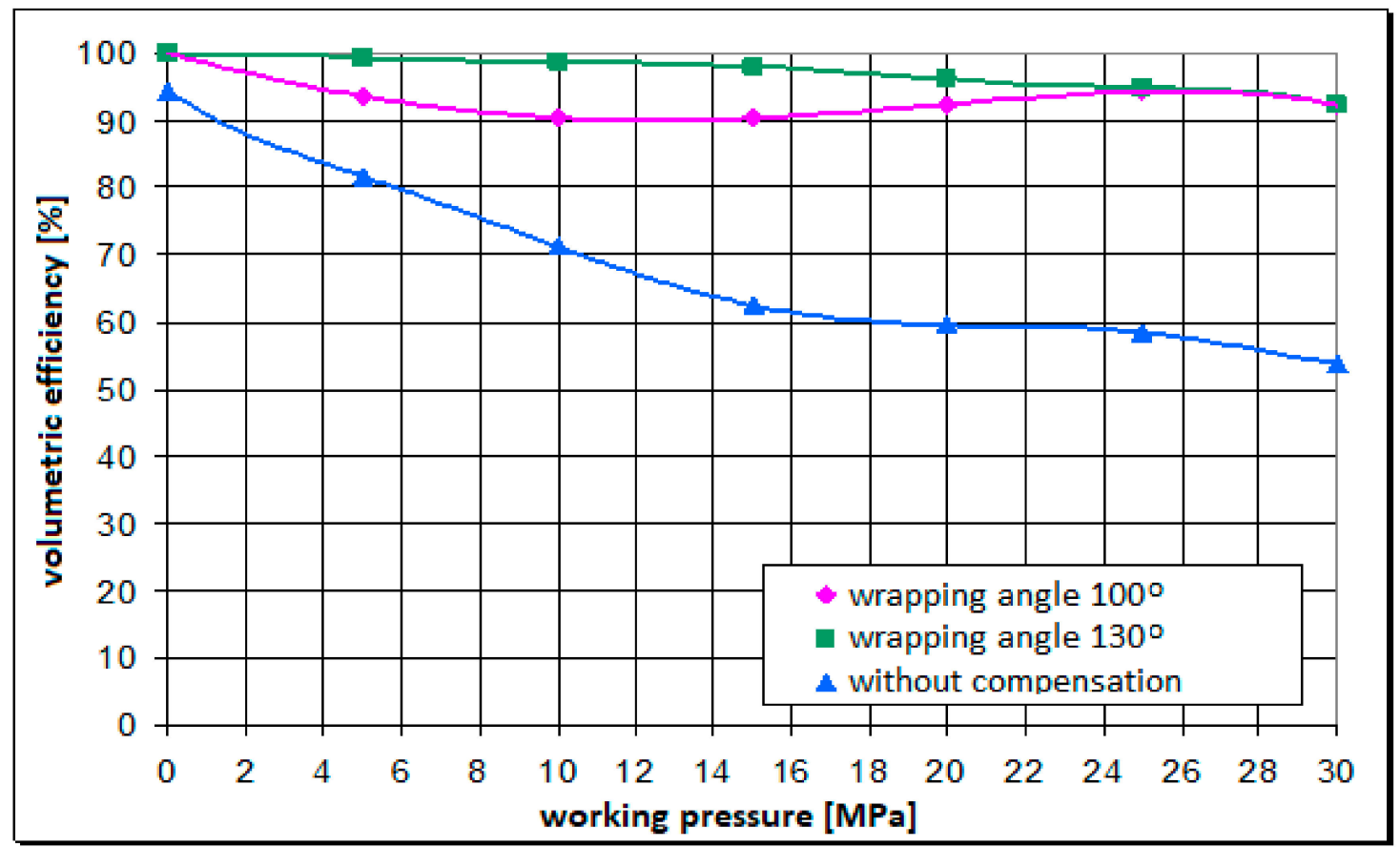

Figure 2. Volumetric efficiency for the conventional pump and for the prototype pumps with circumferential backlash compensation having the wrapping angles $\varphi_{o}=100^{\circ}$ and $130^{\circ}$, with $\mathrm{n}=500 \mathrm{rev} / \mathrm{min}$. [1].

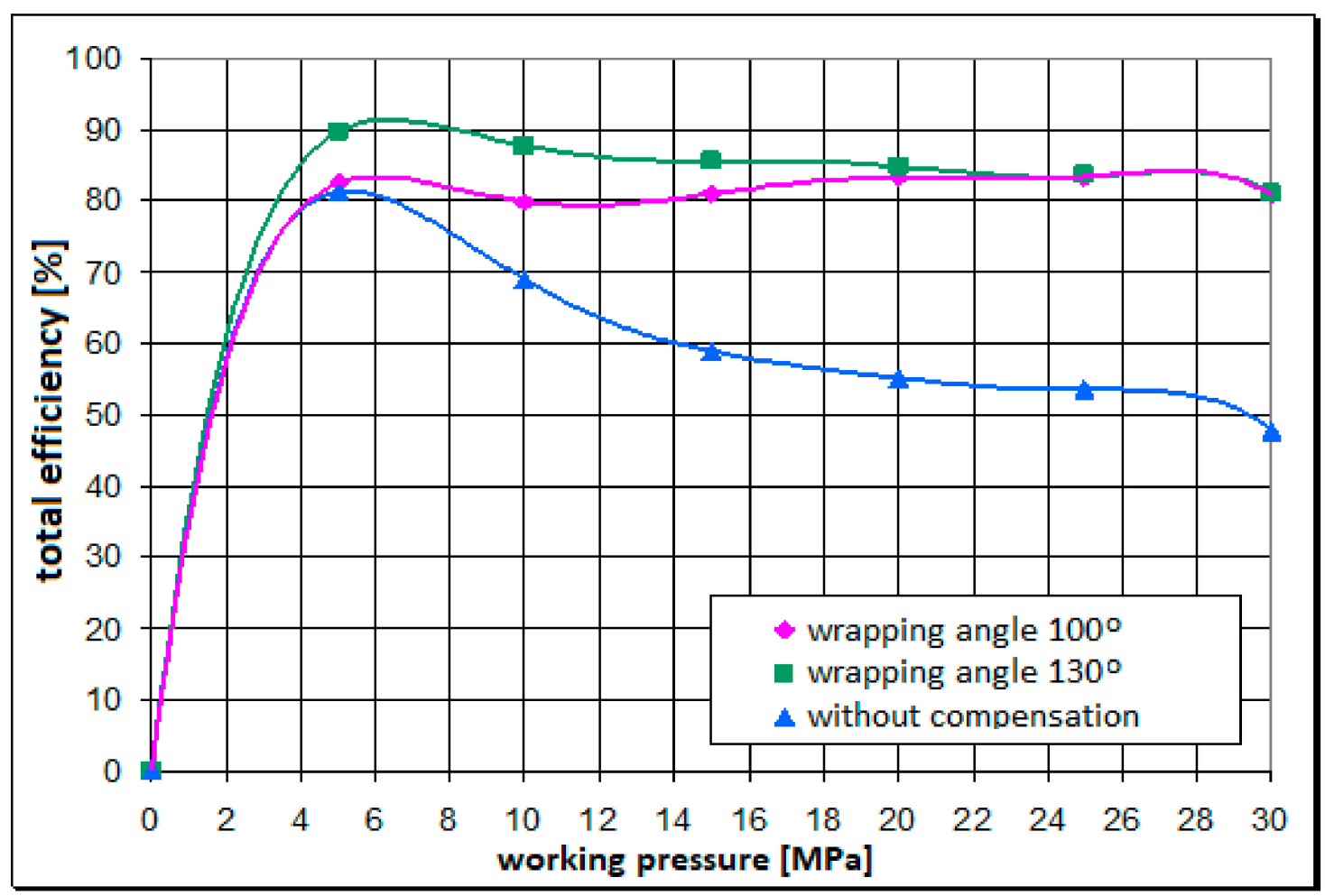

Figure 3. Total efficiency for the conventional pump and for the prototype pumps with circumferential backlash compensation having the wrapping angles $\varphi_{o}=100^{\circ}$ and $130^{\circ}$, with $\mathrm{n}=500 \mathrm{rev} / \mathrm{min}$. [1].

The first design of a pump with circumferential backlash compensation was based on Patent Application No. P.397539 (Patent No. PL221099 [16]). In this design, the lip was initially assumed to have a constant thickness $g_{w}$ of $2 \mathrm{~mm}$ and wrapping angle $\varphi_{o}=130^{\circ}$ (see Figure 4). The patent application was submitted to the patent office at the turn of 2011 
and 2012. The first prototype was tested in 2012. Previously, the idea of caulking around the entire circumference of a gear pump was not analyzed and tested. The first design and construction solution with a new type of compensation was created.

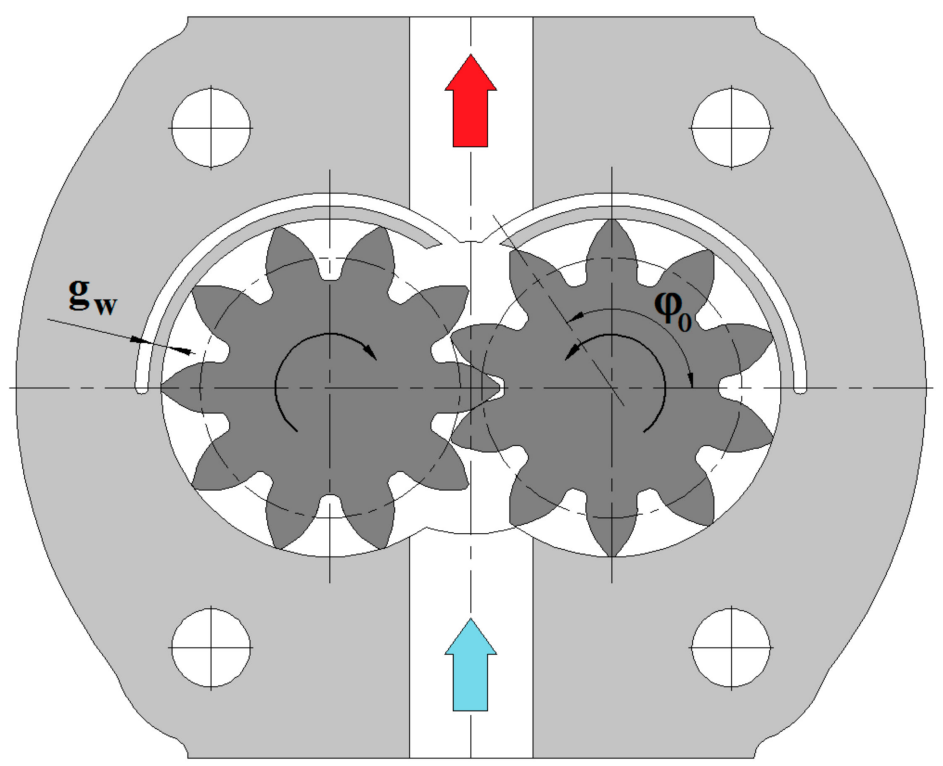

Figure 4. The first version of circumferential compensation with a lip of a constant thickness, according to Patent No. PL221099 (Patent Application No. P.397539 [16]).

The results of the first operating tests of the prototype pump with the circumferential backlash compensation lip demonstrated that the lip is an element particularly prone to damage (see Figure 5), which is manifested in the form of lip fractures in the restraint cross-section (or in the vicinity of this section) [2].
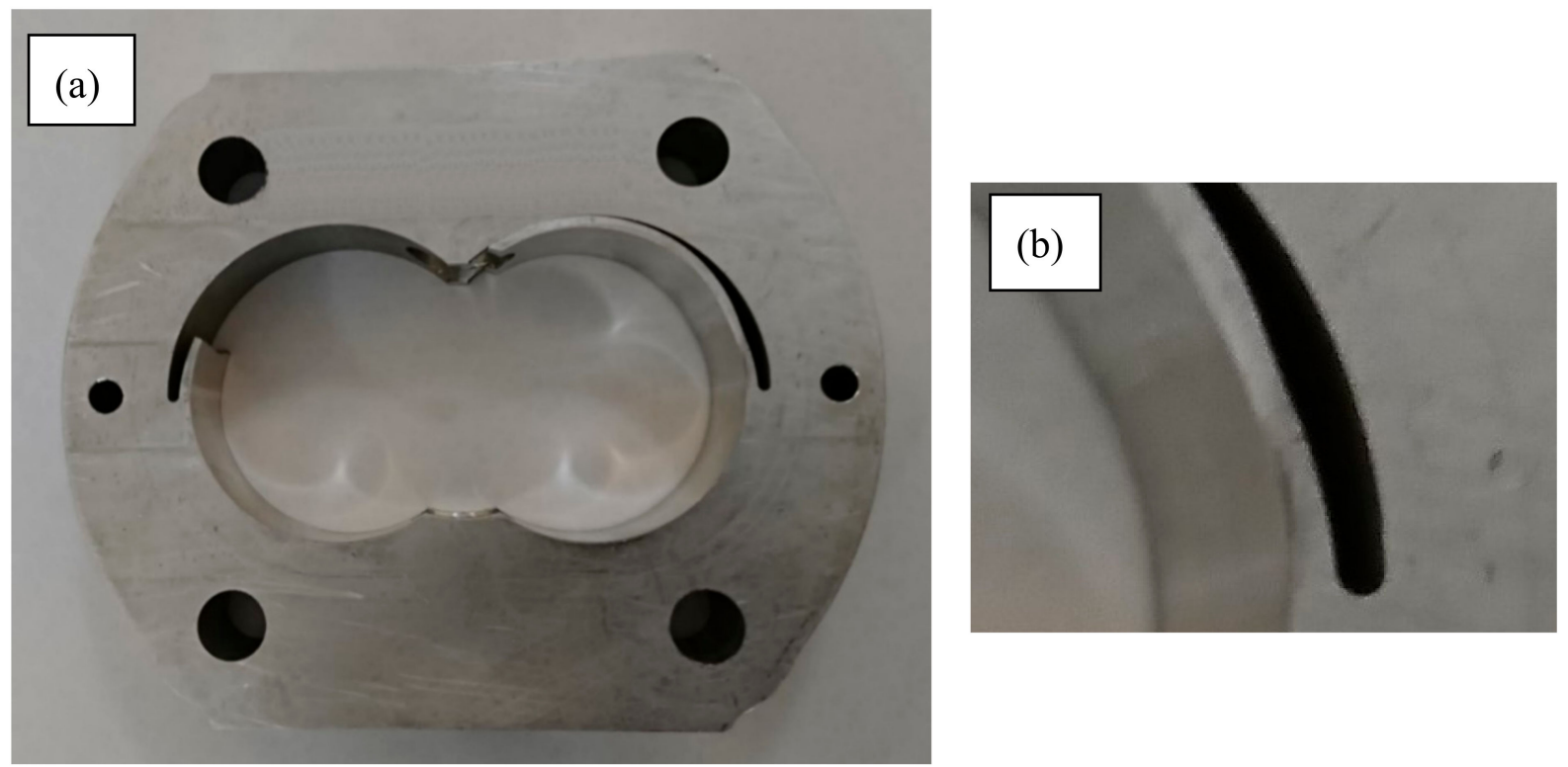

Figure 5. Central body of the first version of circumferential compensation [2]: (a) after durability tests; and (b) view of the cross-section of the reduced compensation lip.

Circumferential compensation is a pioneering solution. Nevertheless, it is still necessary to carry out the strength and durability research works aimed at implementing the concept of circumferential clearance compensation into production. A properly designed 
lip should foremost have a precise and optimally selected thickness, which on the one hand provides the required elasticity and flexibility, and on the other hand-has sufficient strength to resist fatigue stresses.

Some of the first research efforts at identifying the minimum thickness of the lip are described in $[1,3]$, with the latter publication including calculations for a static system which corresponds to the most unfavorable position of the pump gear with respect to the lip: when the cross-section of the lip restraint overlaps with the centerline of one of the gear teeth (Figure 6a). In this case, the lip is subjected to a continuous load $q(\varphi)$, which is the resultant force of the pressure differences on the two sides of the lip (Figure 6b). Three different lip lengths were considered, which corresponded to the length of a circular segment with the wrapping angle $\varphi$ equal to $102^{\circ}, 132^{\circ}$ and $169^{\circ}$, with the lip being in contact with three, four and five teeth, respectively. As described in [15], the result of calculations for a pump with an internal radius $r=26.00 \mathrm{~mm}$ provided the respective values of the required lip thickness $\left(h_{\min }\right)$ at $2.98,3.26$ and $3.99 \mathrm{~mm}$.

a)

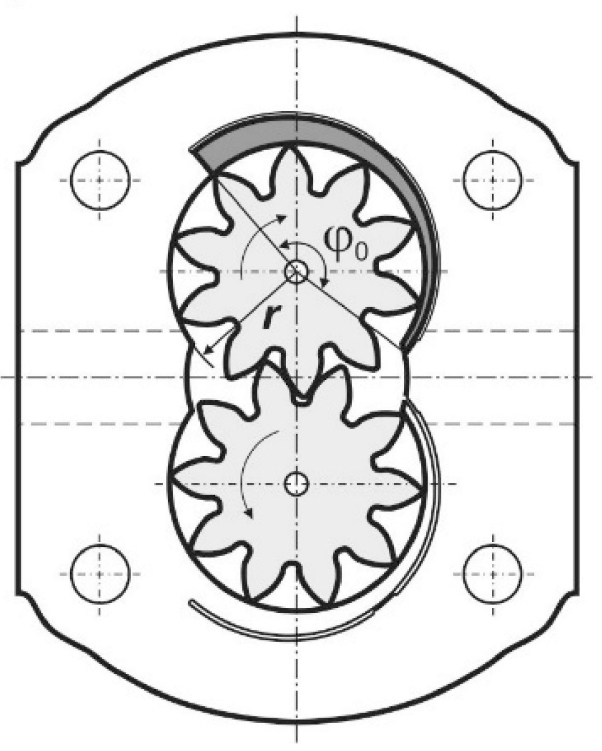

b)

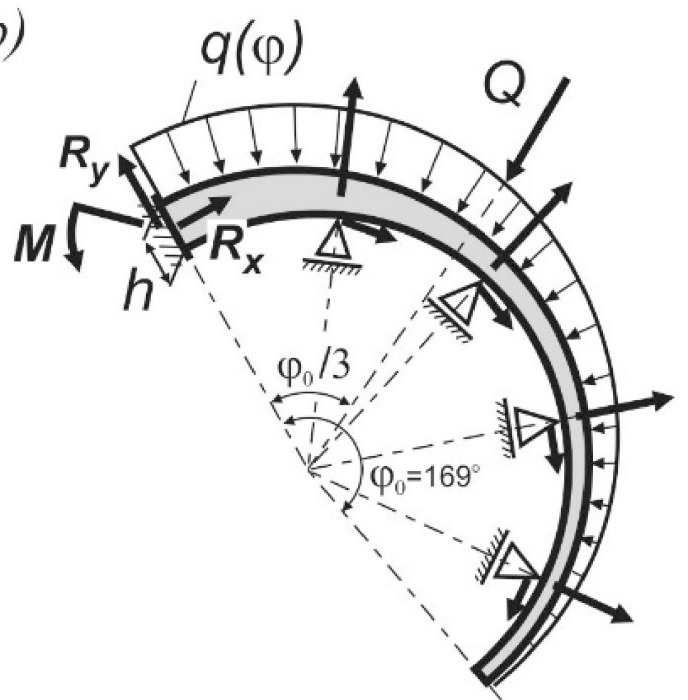

Figure 6. Diagram of the gear pump with circumferential backlash compensation and with the lip (indicated in gray color) having the wrapping angle $\varphi_{o}$ of $169^{\circ}$ : (a) gear position most unfavorable for the loaded lip; and (b) static mechanical system of the lip. Symbols: $h$, lip thickness in the restraint cross-section; $q(\varphi)$, continuous load due to pressure differences on the two lip sides; $Q$, resultant force of the continuous load; $R_{x}, R_{y}, M$, internal forces in the restraint; $r$, radius of the internal working space of the gear body.

Further works on the design model of the pump prototype led to a small modification of this geometry: the radius $r$ of the internal chamber was reduced to $24.90 \mathrm{~mm}$. In the next step, this modification allowed the lip thickness to be increased on the basis of an assumption that the profile of the rod used for the pump body has a uniform geometry. This assumption was also held in this work.

\section{Materials and Methods}

From the perspective of the mechanical system, the lip may be viewed as a cantilever beam which is subjected to pressure pulsations and it is therefore under a continuous fatigue-type load acting on both of its sides

The compensation lip of the design discussed here is particularly prone to fatigue stresses, as it includes a notch which significantly increases local stress values. The theoretical foundations for fatigue-related calculations in such designs were laid by Thum, Buchman and Peterson in the 1930s [17,18]. According to the equations used in this the- 
ory, the so-called fatigue strength is calculated by reducing the strength defined for the structure operated under static conditions. For this purpose, an assumption is made about a number of coefficients which influence the strength of the structure operated under variable load, including the size of the structure, the shape coefficient, the condition of the surface, and the notch sensitivity of the material. By following this method and assuming an adequate model for the variable load on the compensation lip, its minimum thickness can be calculated.

\subsection{Resultant Values of Static Calculations}

By following the calculations presented in publication [3], with the lip wrapping angle $\varphi_{o}=169^{\circ}$, the internal chamber radius $r=24.9 \mathrm{~mm}$ and the maximum pressure in the compensation chamber $p=40 \mathrm{MPa}$, the following values of internal forces in the restraint cross-section are obtained: $N=1132.4 \mathrm{~N}, T=4721.6 \mathrm{~N}$ and $M_{g}=29,197.0 \mathrm{Nmm}$ (Figure 7).

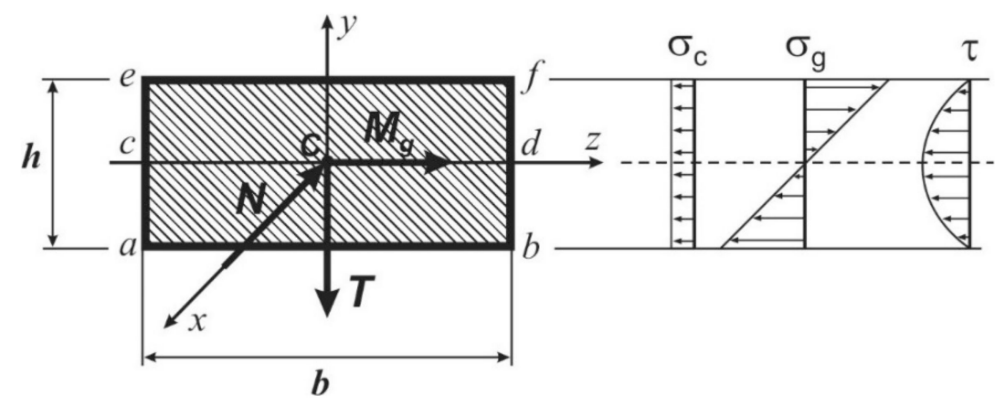

Figure 7. Internal forces in the restraint cross-section and the stress distributions. Symbols: $M_{g}-$ bending moment; $N$-normal force; $T$-shearing force; $C$ - center of the cross-section area; $a-b, c-d$, $e-f$-cross-section layers having characteristic distributions of normal and static stresses.

The strength criterion to permissible normal stresses (tensile or compressive) must allow for the tensile (compressive) and bending stresses simultaneously exerted in the outermost fibers:

$$
\sigma=\left|\sigma_{r}\right|+\left|\sigma_{g}\right| \leq k_{r}
$$

Modifying Equation (6) with the values of normal and bending stresses described with equations:

$$
\sigma_{r}=\frac{N}{b h}, \sigma_{g}=\frac{6 M_{g}}{b h^{2}}
$$

allows an equation describing the minimum beam thickness value $h_{\text {min }}$ :

$$
b k_{r} h_{\text {min }}^{2}-N h_{\text {min }}-6 M_{g}=0
$$

From Equation (8), the actual cross-section width $b=26.3 \mathrm{~mm}$ and the permissible stress value $k_{r}=490 \mathrm{MPa}$ allow the calculation of the minimum cross-section height for static loads:

$$
h_{\text {min }}=\frac{N+\sqrt{N^{2}+24 \cdot b \cdot k_{r} \cdot M_{g}}}{2 \cdot b \cdot k_{r}}=\frac{1132.4+\sqrt{1132.4^{2}+24 \cdot 26.3 \cdot 490 \cdot 29197}}{2 \cdot 26.3 \cdot 490}=3.73 \mathrm{~mm}
$$

The reduced stresses in individual layers of the cross-section are (according to the Huber hypothesis):

$$
\begin{gathered}
\sigma_{\text {red }(a-b)}=\left|-\frac{N}{b h}-\frac{6 M_{g}}{b h^{2}}\right|=\left|-\frac{1132,4}{26.3 \cdot 3.73}-\frac{6 \cdot 29197}{26.3 \cdot 3.73^{2}}\right|=490 \mathrm{MPa} \\
\sigma_{\text {red }(c-d)}=\sqrt{\left(-\frac{N}{b h}\right)^{2}+3\left(\frac{3}{2} \frac{T}{b h}\right)^{2}}=\sqrt{\left(-\frac{1132,4}{26.3 \cdot 3.73}\right)^{2}+3\left(\frac{3}{2} \cdot \frac{4721,6}{26.3 \cdot 3.73}\right)^{2}}=125.5 \mathrm{MPa}
\end{gathered}
$$




$$
\sigma_{\text {red }(e-f)}=\left|-\frac{N}{b h}+\frac{6 M_{g}}{b h^{2}}\right|=\left|-\frac{1132,4}{26.3 \cdot 3.73}+\frac{6 \cdot 29197}{26.3 \cdot 3.73^{2}}\right|=466.9 \mathrm{MPa}
$$

The greatest effort is then observed in the extreme fibers ( $a-b$ and $e-f)$ and these should be the objects of the fatigue calculations.

As already mentioned, the research described in [3] focused only on the calculations and static tests of the lip. This article is the first to focus on dynamic tests which determine the fatigue strength of the lip.

\subsection{Calculations of Minimum Beam Thickness Using the Fatigue Strength Condition}

The fatigue cycle in the cross-section considered here is a purely pulsating load, and the normal stress changes due to the compressive force and the bending moment are not shifted in phase.

Based on [19], the AW7075 material used for the pump body was assumed to have the following mechanical properties: tensile strength $R_{m}=550 \mathrm{MPa}$, bending yield strength $R_{e g}=220 \mathrm{MPa}$, reversed bending fatigue strength $Z_{g o}=150 \mathrm{MPa}$, pulsating bending fatigue strength $Z_{g j}=240 \mathrm{MPa}$ and permissible tensile/compressive pulsating stresses $k_{r j}=k_{c j}=80$ $\div 100 \mathrm{MPa}$. The base number of cycles used to determine the fatigue properties was $n_{z}=$ $10^{8}$ cycles.

As the ratio between the compressive stresses and the bending stresses for layers $a-b$ and $e-f$ is $\sigma_{c} / \sigma_{g \text { max }}<0.05$, the load state was simplified to the form of only cyclically variable pulsating bending (Figure 8 ). In this case, the maximum stresses in the outermost fibers on the tensioned side and on the compressed side are caused only by the bending moment $M_{g}$ and have equal absolute values, while the mean stresses and the stress amplitude are equal at: $\sigma_{m}=\sigma_{a}=\sigma_{\max } / 2$.

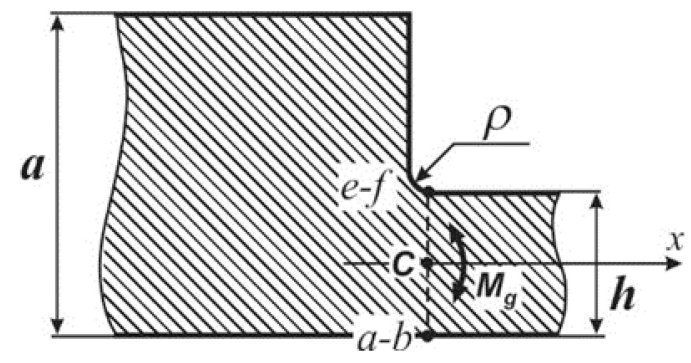

Figure 8. Simplified load scheme assumed for the lip restraint cross-section Symbols: $M_{g}$, variable bending moment; $h$, lip height; $a$, pump body wall thickness; $\rho$, notch fillet radius; $e-f$, $a-b$, extreme fibers carrying the highest loads.

The lip restraint cross-section should assume the presence of a notch with a fillet radius $\rho=0.75 \mathrm{~mm}$ (Figure 8 ). Due to the notch and a substantial surface roughness, the location most prone to fatigue failure is the $e-f$ layer.

The fatigue strength calculations aimed at determining the required cross-section height involve verifying the following three conditions:

(a) The maximum stresses in the cross-section must not exceed the values permitted in the pulsating bending fatigue $\left(k_{g j}\right)$ :

$$
\sigma_{g \max }=\frac{M_{g}}{W_{z g}} \leq k_{g j}
$$

where: $M_{g}=29167 \mathrm{Nmm}, b=26.1 \mathrm{~mm}, k_{g j}=k_{r j}=80 \mathrm{MPa}$.

From this equation the minimum cross-section height $h_{z \min }$ can therefore be approximately calculated as:

$$
h_{z \min }=\sqrt{\frac{6 M_{g}}{b \cdot k_{r j}}}=\sqrt{\frac{6 \cdot 29167}{26.3 \cdot 80}}=9.12 \mathrm{~mm}
$$


(b) The fatigue factor of safety $x_{z}$, being related to the bending fatigue strength and the coefficients defining the conditions of the structure in fatigue operation, must not be smaller than its required value $x_{z w}$. For the load increase of $\sigma_{a} / \sigma_{m}=$ const, this condition is expressed with the following equation:

$$
x_{z}=\frac{Z_{g o}}{\beta \gamma \sigma_{a}+\sigma_{m}\left(\frac{2 Z_{g o}}{Z_{g j}}-1\right)} \geq x_{z w}
$$

(c) The fatigue factor of safety $x_{z}$ must also satisfy the relationship for yield strength during fatigue bending:

$$
x_{z}=\frac{R_{e g}}{\beta \gamma \sigma_{a}+\sigma_{m}} \geq x_{z w}
$$

The required safety factor $x_{z w}$ found in Equations (15) and (16) is calculated as a product of four individual component coefficients $x_{i}$. Their values in the case considered here are: $x_{1}=1.5$-reliability factor, $x_{2}=1.10$ - object importance coefficient, $x_{3}=1.10$ material uniformity coefficient, $x_{4}=1.00$-dimension preservation coefficient. In addition, the value of factor $x_{z w}$ is increased by $40 \%$ for light alloys and non-ferrous metals (in accordance with the recommendations in [19]), and its final value is: $x_{z w}=1.151 .101 .10$ $1.001 .40=1.95$.

The values of the remaining coefficients were obtained in the following manner:

- Cross-section area coefficient: $\gamma=1.45$-was determined from graph 8.5 in [19] for shaft diameter $d=17.5 \mathrm{~mm}$, equivalent to the area of the lip restraint cross-section: $b \times h=26.3 \times 9.12=240 \mathrm{~cm}^{2}$. This coefficient is defined as the relationship between the fatigue strength of the specimen (or element) having a certain cross-sectional diameter and the strength of the standard specimen, made of the same material and having a diameter of 7-10 $\mathrm{mm}$. In the case of elements having their cross-sectional shape different than circular, the applied graphs are based on the equivalent crosssectional area.

- Fatigue stress concentration factor: $\beta=1.81$-was calculated from the equation: $\beta=\beta_{k} \cdot \beta_{p}=\left[1+\eta\left(\alpha_{k}-1\right)\right] \beta_{p}$, where $\beta_{k}$ is the value of fatigue strength reduction due to the notch and is defined on the basis of the relationship between the fatigue strength of the unnotched specimen and the fatigue strength of the notched specimen, and $\beta_{k}$ the surface factor-is defined as the relationship between the strength of the polished specimen and the strength of the machined element. Factor $\beta_{k}$ was calculated on the basis of: notch sensitivity coefficient $\eta=0.53$-assumed on the basis of Graph 8.10 in [19] for notch radius $\rho=0.75 \mathrm{~mm}$; stress-concentration factor $\alpha \mathrm{k}=2.03$-assumed as per Graph 8.31 in [19], for relationships $\rho / h=0.75 / 9.12 \approx 0.08$ and $\mathrm{a} / \mathrm{h}=18.00 / 9.12$ $\approx 2.0$, where $\mathrm{a}=18 \mathrm{~mm}$ is the pump body wall thickness (Figure 8 ); surface factor $\beta \mathrm{p}$ $=1.17$-assumed on the basis of Graph 3.53 in [20] for material ultimate strength Rm $=550 \mathrm{MPa}$ and surface porosity obtained for a rough environment, which is a method equivalent to the electrical discharge drilling of the compensation chamber.

Conditions (12) and (13), with the assumption that $\sigma_{m}=\sigma_{a}=\sigma_{\max } / 2$, may serve to define the maximum stresses possible in the lip restraint cross-section:

- From Condition (12):

$$
\sigma_{\text {max }} \leq \frac{2 \cdot Z_{g o}}{x_{z w}\left(\beta \gamma+\frac{2 \cdot Z_{g o}}{Z_{g j}}-1\right)}=\frac{2 \cdot 150}{1.95\left(1.81 \cdot 1.45+\frac{2 \cdot 150}{240}-1\right)}=53.6 \mathrm{MPa}
$$

- From Condition (13):

$$
\sigma_{\max } \leq \frac{2 \cdot R_{e g}}{x_{z w}(\beta \gamma+1)}=\frac{2 \cdot 220}{1.95(1.81 \cdot 1.45+1)}=62.3 \mathrm{MPa}
$$


The permissible stress must be assumed to be the lower of the two values: $\sigma_{\max }=53.6 \mathrm{MPa}$. If Condition (9) is applied, the new minimum lip height is obtained:

$$
h_{z \min }=\sqrt{\frac{6 M_{g}}{b \cdot \sigma_{g \max }}}=\sqrt{\frac{6 \cdot 29167}{26.3 \cdot 53.6}}=11.14 \mathrm{~mm},
$$

The obtained value $h_{z \text { min }}$ is significantly different than the value defined in Equation (14), and has an influence on the value of factor $\beta$ used in Equations (15) and (16). Its recalculation leads to: $\beta=1.76$, and its application in Equations (15) and (16) allows the value of the permissible stress in the cross-section to be recalculated, leading to: $\sigma_{\max }=55.0 \mathrm{MPa}$. If Relationship (13) is used for this value, the final result is:

$$
h_{z \min }=\sqrt{\frac{6 M_{g}}{b \cdot \sigma_{g \max }}}=\sqrt{\frac{6 \cdot 29167}{26.3 \cdot 55.0}}=11.00 \mathrm{~mm},
$$

In this case, the difference of $h_{z \min }$ between the results obtained from Equations (19) and (20) is sufficiently small for its influence to be neglected in the stress concentration factor $\beta$.

An identical method was used to calculate the minimum thicknesses for smaller length lips, i.e., in the cases of the wrapping angles $132^{\circ}$ and $102^{\circ}$. The results of these calculations are shown in Table 1.

Table 1. Working parameters and results of fatigue calculations for three lip variants in a rotary pump with circumferential backlash compensation.

\begin{tabular}{cccccc}
\hline $\begin{array}{c}\text { Lip Wrapping } \\
\text { Angle }\left(\varphi_{o}\right)\end{array}$ & $\begin{array}{c}\text { Working Pressure } \\
\text { in the Pump } \\
\text { Compensation } \\
\text { Chamber }\left(p_{2}\right) \\
{[\mathrm{MPa}]}\end{array}$ & $\begin{array}{c}\text { Pressure in the } \\
\text { Tooth Space at the } \\
\text { Lip Restraint }\left(p_{1 k}\right) \\
{[\mathrm{MPa}]}\end{array}$ & $\begin{array}{c}\text { Fatigue Bending } \\
\text { Moment }\left(\boldsymbol{M}_{g z}\right) \\
{[\mathrm{Nm}]}\end{array}$ & $\begin{array}{c}\text { Permissible Fatigue } \\
\text { Stresses in the } \\
\text { Cross-Section of the } \\
\text { Lip }\left(\sigma_{z \text { max }}\right)[\mathrm{MPa}]\end{array}$ & $\begin{array}{c}\text { Lip Minimum } \\
\text { Height (Thickness) } \\
\text { in the Restraint } \\
\text { Cross-Section } \\
\left(h_{z \text { min }}\right)[\mathrm{mm}]\end{array}$ \\
\hline $\mathbf{1 0 2}^{\circ}$ & 40 & 20 & 12.8 & 64.9 & $\mathbf{1 0 . 7 0}$ \\
$\mathbf{1 3 2}^{\circ}$ & 40 & 13.3 & 19.5 & 60.4 & $\mathbf{1 0 . 8 2}$ \\
$\mathbf{1 6 9}^{\circ}$ & 40 & 6.7 & 29.1 & 53.6 & $\mathbf{1 1 . 0 0}$ \\
\hline
\end{tabular}

\section{Experimental Tests}

The minimum lip thickness calculated in the previous section required confirmation in experimental tests. The tests were performed for three pump bodies with lips which have wrapping angles equal to $132^{\circ}$, in which one lip was subjected to static tests, and the other-to fatigue tests. The static tests were aimed at defining the load-displacement diagram during lip bending (Figure 9a,b). The values of maximum forces are shown in Table 2.

Table 2. Results of static bending tests and fatigue loading tests for the lip compensating circumferential backlash in a gear

\begin{tabular}{|c|c|c|c|c|c|c|c|}
\hline \multirow[b]{3}{*}{$\begin{array}{l}\text { Specimen } \\
\text { No. }\end{array}$} & \multirow[b]{3}{*}{$\begin{array}{c}\text { Lip Wrapping } \\
\text { Angle } \\
\left(\varphi_{o}\right)\end{array}$} & \multirow{3}{*}{$\begin{array}{c}\text { Cross-Section } \\
\text { Dimensions } \\
(b \times h) \\
{[\mathrm{mm}]}\end{array}$} & \multirow{3}{*}{$\begin{array}{l}\text { Static Tests } \\
\text { Maximum } \\
\text { Force } \\
\text { Fs } \operatorname{Max}[\mathrm{N}]\end{array}$} & \multicolumn{4}{|c|}{ Fatigue Tests } \\
\hline & & & & \multicolumn{2}{|c|}{ Last Test without Failure } & \multicolumn{2}{|c|}{ Test Ended with Failure } \\
\hline & & & & $\begin{array}{l}\text { Maximum } \\
\text { Force } \\
F z \operatorname{Max}[\mathrm{N}]\end{array}$ & $\begin{array}{c}\text { Banding } \\
\text { Stresses } \\
\sigma z M a x \\
{[\mathrm{MPa}]}\end{array}$ & $\begin{array}{c}\text { Maximum } \\
\text { Force } \\
F z \operatorname{Max}[\mathrm{N}]\end{array}$ & $\begin{array}{c}\text { Banding } \\
\text { Stresses } \\
\sigma z M a x \\
{[\mathrm{MPa}]}\end{array}$ \\
\hline 1 & $132^{\circ}$ & $26.3 \times 5.9$ & 2480 & 850 & 96 & 900 & 102 \\
\hline 2 & $132^{\circ}$ & $26.1 \times 5.1$ & 1940 & - & - & 450 & 69 \\
\hline 3 & $132^{\circ}$ & $26.1 \times 5.1$ & 2382 & 1300 & 198 & 1400 & 214 \\
\hline
\end{tabular}
pump. 


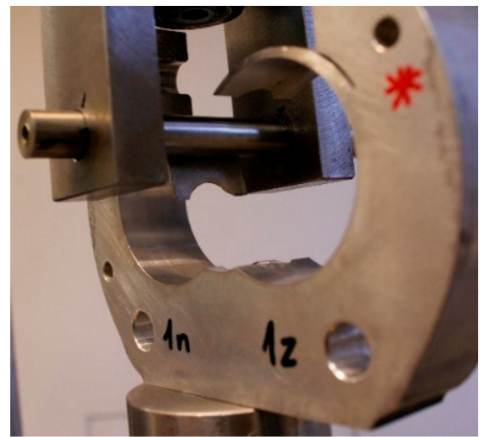

(a)

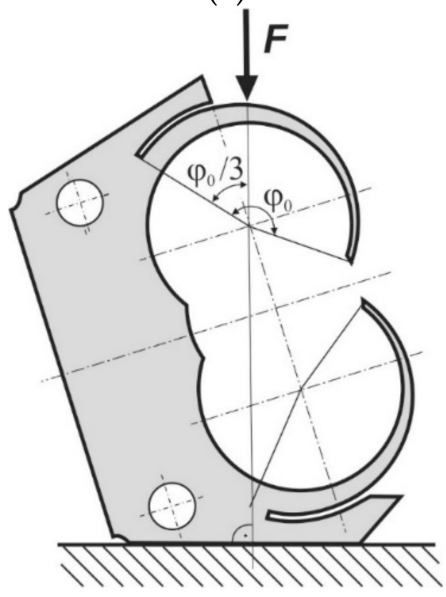

(c)

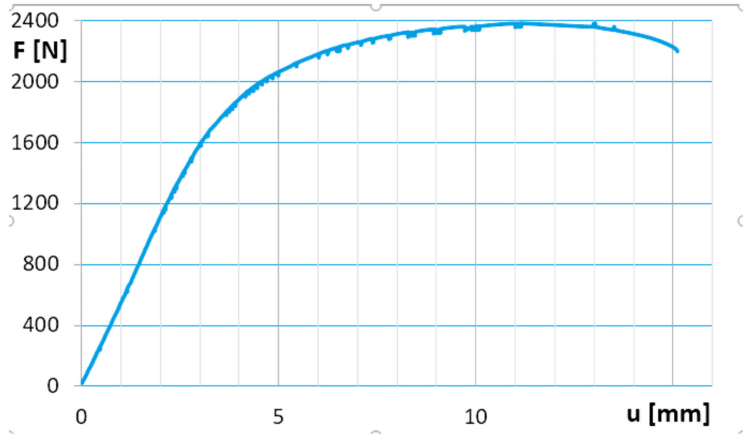

(b)

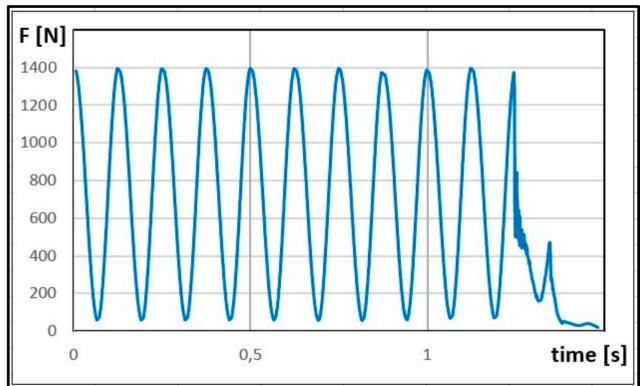

(d)

Figure 9. Experimental tests of the lip compensating circumferential backlash in a pump: (a) pump body during the static loading test, (b) static loading diagram for specimen 1, (c) fatigue test diagram; and (d) fatigue failure diagram at $F_{z \text { min/max }}$ $=50 / 1400 \mathrm{~N}, f=10 \mathrm{~Hz}, N=53,305$ cycles for Specimen 3 .

The fatigue tests were performed for pump bodies prepared in a manner to allow loading of the lip in accordance with the assumed theoretical model, i.e., with a concentrated force applied at an angular distance of $1 / 3$ of the total lip span angle (Figure 9c). In this case, the concentrated force $F$ applied at this point corresponds to the resultant force $Q$ shown in Figure 6. The force used was sinusoidally variable at a frequency $f=10 \mathrm{~Hz}$. Each test series was performed until the number $\mathrm{N}=2.5 \times 106$ of cycles was reached (which corresponds to 2.5 times the number of cycles used in the pump wear margin tests) or until lip failure. If failure did not occur, the subsequent test was performed at a maximum force $F_{z \text { max }}$ being 50 or $100 \mathrm{~N}$ greater than the force applied in the previous test. The minimum force $F_{z \min }$ in the cycle was always $50 \mathrm{~N}$. The tests were performed on a universal MTS 858.02 Mini Bionix machine which has an operating range of $0-15 \mathrm{kN}$.

In the case of both the first and the second lip (test specimens from Pump Bodies 1 and 2), the fatigue tests were performed with the use of a slightly beveled tool (shaft) pressing against the lip in order to demonstrate the influence of an imprecise lip construction, which results in non-uniform load distribution on the lip surface. The test results are provided in Table 2. The stresses were calculated with allowance solely for the bending moment, as was the case in prior theoretical calculations. Specimen 2 had already failed in the first test.

In the case of Specimen 3, the bevel in the tool was removed so as to provide uniform load distribution on the lip surface. This specimen failed at force $F_{z \max }=1400 \mathrm{~N}$, and its failure diagram is shown in Figure 9d. The last test, in which failure did not occur, was performed at $F_{z \max }=1300 \mathrm{~N}$.

The effect of the non-uniform load can be observed on the lip fracture-it takes the form of a unilaterally developed fatigue cracks and surface slips in the immediate fracture zone (Figure 10). 


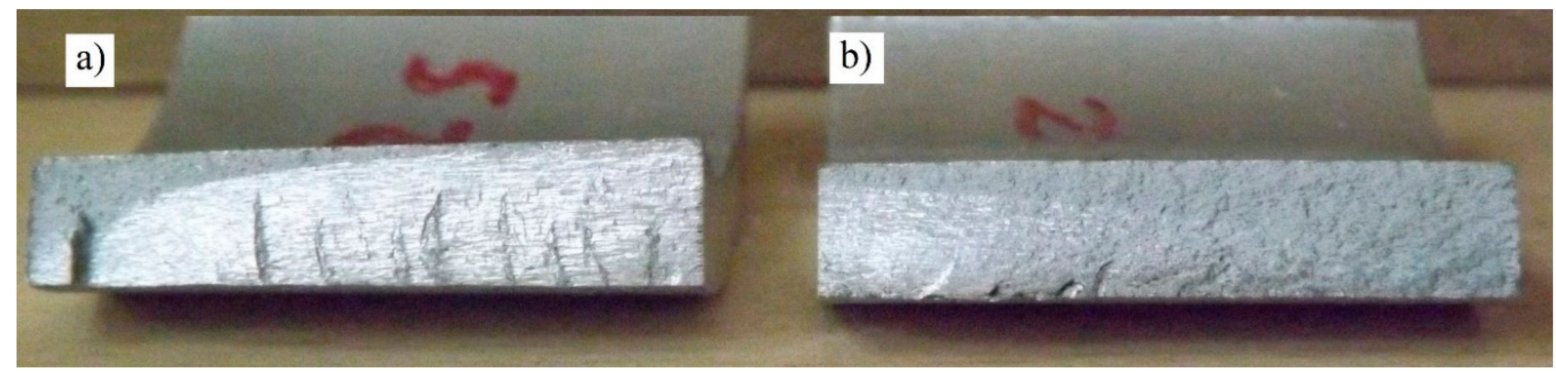

Figure 10. Lip fractures at fatigue failure: (a) for Specimen 1 (non-uniform load) at breaking force $F_{z \max }=450 \mathrm{~N}$; (b) for Specimen 3 (uniform load) at breaking force $F_{z \max }=1400 \mathrm{~N}$.

\section{Conclusions}

The theoretical calculations discussed in Section 2 allowed the identification of the theoretical minimum restraint thickness for the compensation lip. For pumps with lips having lengths defined by the wrapping angle $\varphi$ equal to $102^{\circ}, 132^{\circ}$ and $169^{\circ}$, these thickness values were $10.70,10.82$ and $11.00 \mathrm{~mm}$, respectively. It should be noted, however, that the calculations were performed for the material fatigue failure parameters for the base number of cycles being $n_{z}=10^{8}$, while at an expected lower number of cycles (e.g., the number used in wear margin tests of rotary pumps, i.e., $n_{z}=10^{6}$ cycles), the values of fatigue strength or permissible stresses are higher and thus the calculated $h_{z} \min$ would be lower. However, precise identification of $h_{z \min }$ for the cycle number $n_{z}=2 \times 10^{6}$ is not possible, as no data are available on the values of the relevant properties of the AW7075 alloy for this number of cycles.

The experimental tests discussed in Section 3 demonstrated that at the number of fatigue cycles $n_{z}=2.5 \times 10^{6}$, the actual maximum stresses which the compensating lip of specimen 3 can carry are $\sigma_{z \max }=198 \mathrm{MPa}$. They are significantly higher than the permissible stress value at fatigue bending $\left(k_{g j}=k_{r j}=80 \mathrm{MPa}\right)$ assumed in Equation (8). The safety stress margin is thus $n=\sigma_{z m a} / k_{g j}=2.47$.

The value of the strength safety factor $n$ obtained for the investigated design element is the most important (if not the only important) result of the strength tests. It provides information on whether during its destruction the tested element transferred the stress value assumed as the limit value for the particular material (in this case it is $k_{g j}=k_{r j}=$ $80 \mathrm{MPa}$ ), and if yes, then how much the value was exceeded. In the case of the presented test results, the limit value was exceeded approximately 2.5 times, and this value clearly indicates that the assumed lip geometry is proper. On the one hand, it allows a sufficient safety margin for the pump operated in actual conditions (for this purpose the factor $n$ should have a value higher or equal to 1.5). On the other hand it does not lead to the adverse consequences of using a lip of excessive thickness if the margin was three times $k_{g j}$ or more (this would entail the need to use pump body walls of greater thickness, and therefore to increase the pump mass and the manufacturing costs).

The lip thickness $h=5.10 \mathrm{~mm}$ can be therefore believed sufficient for a pump life corresponding to the assumed $n_{z}$ number of fatigue cycles. At lower lip thickness values the lip will fail (see Figure 5). However, it must be emphasized that any construction inaccuracies related to the shape and dimensions of the lip, and in particular to the lateral dimension of its upper surface, will cause load distribution to be non-uniform and in such case the fatigue strength will radically decrease. This observation is based on the results of fatigue tests for Specimens 1 and 2, which had this type of defect, and which failed under a breaking stress two- or even three-fold smaller than the stress applied to Specimen 3 (see Table 2). The significantly different results observed in the case of Specimens 1 and 2 also indicate a substantial dispersion of the fatigue test-related results. Importantly, the type of the applied test did not allow the material of the lip to be subjected to plastic necking, which is observed in actual pump operating conditions and which precedes eventual lip failure. This fact also indicates that the actual designs based on the results of these tests 
should involve an adequately high safety factor $(n>1.5)$. In the case of high-pressure pumps, i.e., pumps working at pressures exceeding $30 \mathrm{MPa}$, integrated lips may also be considered as an alternative $[2,21,22]$. Structures of this type allow greater loads, as radial forces occurring in opposite lips cancel each other. Another factor affecting the fatigue strength of a beam functioning as a compensation lip is the design-related notch. Its negative influence may be reduced by increasing its radius $\rho$ (see Figure 8), e.g., by providing the lip end with a drilled opening which would have a diameter greater than the width of the compensation chamber. Such a solution has an additional positive effect by increasing the smoothness of the surface at the bottom of the notch.

It should also be noted that the obtained results are based on certain geometrical assumptions behind the pump model and the lip load system, as well as on the estimation accuracy for the values of the fatigue coefficients, which have a significant influence on the simplifications in theoretical calculations. More accurate theoretical calculations, allowing for example the prediction of lip life, would require the determination of the crack growth rate equation. Since the lip geometry is complex, it would be necessary to apply numerical calculations for this, as well as derive the dimensionless geometry factor for the lip. It is necessary to calculate the stress intensity range. On the other hand, the experimental studies, due to the observed scatter of the results, require conducting studies on a large number of samples, allowing for statistical processing of the results. Such tests are planned in the next stage of work.

Author Contributions: Conceptualization, P.O. and G.C.; methodology, P.O., G.C. and L.K.; software, G.C.; validation, P.O., G.C. and L.K.; formal analysis, G.C. and L.K.; investigation, P.O., G.C. and L.K.; resources, P.O., G.C. and L.K.; data curation, G.C.; writing-original draft preparation, P.O. and G.C.; writing-review and editing, P.O. and G.C.; visualization, P.O. and G.C.; supervision, P.O.; project administration, P.O.; funding acquisition, P.O. and G.C. All authors have read and agreed to the published version of the manuscript.

Funding: This research received no external funding.

Institutional Review Board Statement: Not applicable.

Informed Consent Statement: Not applicable.

Data Availability Statement: Accepted and complied with.

Acknowledgments: The authors would like to acknowledge the administrative and editing support of this article by Paweł Bury.

Conflicts of Interest: The authors declare no conflict of interest.

\section{References}

1. Osiński, P. High-Pressure and Low-Pulsation External Gear Pumps (in Polish); Wrocław University of Science and Technology Publishing House: Wrocław, Poland, 2013; ISBN 978-83-7493-815-0.

2. Osiński, P. High-Performance Gear Pumps (in Polish); Wrocław University of Science and Technology Publishing House: Wrocław, Poland, 2019; ISBN 978-83-7493-100-7.

3. Osiński, P.; Chruścielski, G. Strength calculations of an element compensating Circumferential backlash in the external gear pump. J. Theor. Appl. Mech. 2016, 54, 251. [CrossRef]

4. Borghi, M.; Zardin, B.; Specchia, E. External Gear Pump Volumetric Efficiency: Numerical and Experimental Analysis; SAE Technical Paper: No. 2009-01-2844; SAE: Warrendale, PA, USA, 2009. [CrossRef]

5. Frosina, E.; Senatore, A.; Rigosi, M. Study of a High-Pressure External Gear Pump with a Computational Fluid Dynamic Modelling Approach. Energies 2017, 10, 1113. [CrossRef]

6. Ivantysyn, J.; Ivantysynova, M. Hydrostatic Pumps and Motors, Principles, Designs, Performance, Modelling, Analysis, Control and Testing; Akademia Books International: New Delhi, India, 2002.

7. Osiński, P.; Rutański, J.; Bury, P.; Cieślicki, R. Acoustic tests of type KPF1 high-pressure external gear pumps. Tech. Trans. 2020, 13. [CrossRef]

8. Osiński, P.; Bury, P.; Cieślicki, R. Optimizing the Break-in Process of High-Pressure Gear Pumps. In Advances in Hydraulic and Pneumatic Drives and Control 2020 (NSHP 2020), Poland; Stryczek, J., Warzyńska, U., Eds.; Lecture Notes in Mechanical Engineering; Springer: Cham, Switzerland, 2020. [CrossRef]

9. Judin, E.M. Gear Pumps (in Polish); PWT: Warsaw, Poland, 1958. 
10. Kollek, W. Gear Pumps—Design and Operation (in Polish); Ossolineum: Wrocław, Poland, 1996.

11. Śliwiński, P. The influence of water and mineral oil on mechanical losses in the displacement pump for offshore and marine applications. Pol. Marit. Res. 2018, 25, 178-188. [CrossRef]

12. Zardin, B.; Natali, E.; Borghi, M. Evaluation of the Hydro-Mechanical Efficiency of External Gear Pumps. Energies 2019, 12, 2468. [CrossRef]

13. Toet, G.; Johnson, J.; Montague, J.; Torres, K.; Garcia-Bravo, J. The Determination of the Theoretical Stroke Volume of Hydrostatic Positive Displacement Pumps and Motors from Volumetric Measurements. Energies 2019, 12, 415. [CrossRef]

14. Stryczek, S. State-of-the-art and trends in the development of the hydraulic drive (in Polish). Przeglad Mech. 1988. [Part 1] vol. 9, pp. 5; [Part 2] vol. 10, pp. 20; [Part 3] vol. 12, pp. 13; [Part 4] vol. 13, pp. 11; [Part 5] vol. 14, pp. 10; [Part 6] vol. 15, pp. 26; Warszawa 1988

15. Stryczek, J.; Bednarczyk, S.; Biernacki, K. Gerotor pump with POM gears: Design, production technology, research. Arch. Civ. Mech. Eng. 2014, 14, 391. [CrossRef]

16. Wiczkowski, E.; Osiński, P.; Kollek, W.; Kania, A. External Gear Pump (in Polish). Poland Patent 221099, 22 December 2011.

17. Thum, A.; Buchmann, W. Dauerfestigkeit und Konstruktion; VDI GMBH: Berlin, Germany, 1932.

18. Peterson, R.E.; Wahl, A.M. Overcoming fatigue of shafts at press-fitted units. Mach. Des. 1934, 6, 25.

19. Niezgodziński, M.E.; Niezgodziński, T. Calculations of Fatigue Strength for Machine Elements (in Polish); PWN: Warsaw, Poland, 1973.

20. Kocańda, S.; Szala, J. Basic of Calculations of Fatigue Strength (in Polish); PWN: Warsaw, Poland, 1985.

21. Osiński, P.; Cieślicki, R.A. External Gear Pump (in Polish). Poland Patent 230845, 10 August 2016.

22. Osiński, P. Gear Pump (in Polish). Poland Patent 223649, 22 July 2013. 